\title{
DE LA TRANSFIGURACIÓN DEL MÁXIMO \\ DERECHO A TODO: TEMOR, ESPERANZA Y CÁLCULO DE UTILIDAD
}

Víctor Manuel Pineda*

Resumen: Este ensayo tiene por objeto mostrar las diversas significaciones que tiene el concepto de utilidad en la filosofía de Spinoza. Por un lado se exhibe como una tendencia de la naturaleza humana a buscar a toda costa todo aquello que permita prolongar la vida de los individuos; por otro lado se despliega como aquello que suministra el mayor número de prejuicios de un individuo: esta búsqueda ávida conduce al terreno de la imaginación más delirante. Es aquí donde cobra importancia la transfiguración del máximo derecho a todo y los dos sujetos que lo encarnan: los individuos y la sociedad política. Spinoza intenta resolver la paradoja entre la maximización del poder individual y la maximización del conflicto, proponiendo un nuevo sujeto del máximo derecho, la multitud.

Conceptos clave: Utilidad, derecho, temor, esperanza, deseo.

"Para vivir seguros y lo mejor posible, los hombres tuvieron que unir necesariamente esfuerzos. Hicieron, pues, que el derecho a todas las cosas, que cada uno tenía por naturaleza, lo poseyeran todos colectivamente y que en adelante ya no estuviera determinado según la fuerza del apetito de cada individuo, sino según el poder y la voluntad de todos a la vez".

Tratado Teológico-Político, Cap. XVI, II.

\section{La relevancia antropológica del concepto de utilidad}

El tópico surge en un pasaje señaladamente crítico de la filosofía de Spinoza, el Apéndice de la parte 1 de la Ética. Se muestra unido a argumentos que esgrime en contra de las grandes nociones teológico-metafísicas y en torno a declaraciones que reprueban al estupor, la superstición y la vanidad

* Profesor investigador en la Universidad Michoacana de San Nicolás de Hidalgo, Morelia, México. 
humanas; el fragmento presenta también un elogio de las matemáticas, a las que atribuye un poder demoledor en contra de todo tipo de tendencias de la imaginación: "todos los hombres nacen ignorantes de las causas y que todos tienen apetito de buscar su utilidad" (Spinoza 15, Apéndice del Libro 1, c, p. 68). Al mismo tiempo que denuncia las consecuencias de ese eclipse de la razón, se ocupa de exhibir el mecanismo con el que forman prejuicios que orientan a los individuos en las acciones de tipo práctico ${ }^{1}$. Ese curso expositivo del concepto de utilidad le confiere una razón de ser a la perspectiva con la que Spinoza trata muchas de las cuestiones éticas, formuladas a manera de crítica de las pretensiones del finalismo y como una impugnación de los fundamentos metafísicos de las afecciones.

La búsqueda de utilidad es, de entrada, una ciega inclinación que parte de la dualidad medios-fines, que imagina al hombre al centro de los planes de una divinidad que todo lo hace en función del hombre, pues el conocimiento inadecuado se alimenta de ficciones antropomórficas derivadas de esa dualidad. En esa visión de las cosas y de los acontecimientos, éstos no aparecen como instrumentos de nuestros apetitos sino como fragmentos de realidad que pertenecen a un orden que se llega a explicar como un concierto de causas misteriosas, que están dirigidas por un buen Dios que todo nos concede, o perseguirnos con su no menos insondable ira. El alegato en contra del finalismo no tiene otro propósito que el de discutir las consecuencias que posee en relación a la imagen que el hombre posee de las cosas, pues a esas alturas del libro I de la Ética, Spinoza ya ha dado por refutada cualquier otro tipo de causalidad que no sea la que ha demostrado previamente, es decir, todas las modalidades derivadas del concepto de causa sui (Spinoza 15 E. 1, def. 1 p. 39; axiomas 1-5 p. 40, E. 1, proposiciones. 15-18, pp. 49-55). Subrayamos el hecho de que se trata de una imagen de las cosas y no de causas, pues en esta tendencia a ver cosas y no causas -o causas falsas, como la causa final- es la que vuelve a un individuo ignorante y supersticioso: la búsqueda de utilidad es planteada como una sujeción frente a las cosas más inmediatas, las que nos empujan a un interés por todo aquello que se nos revela como alimento, que ofrece confianza, poder o que, por lo menos, promete alejar la fuente de nuestros temores. Spinoza no censura esa búsqueda ávida, pues sabe que se trata de una prescripción de la naturaleza humana y se propone comprender cómo opera a nivel subjetivo, el tipo de pasiones que excita y cómo llega a elaborar la imaginación esa búsqueda interesada. Al declarar que una fuente de nuestros prejuicios es el interés inmediato por las cosas, se aleja del tratamiento clásico del interés como una de las formas de saber "menos virtuosas". Todo es práctico y todo es, en esa misma medida, interesado. Incluso la teoría es una expresión clara del interés, aunque los bienes sobre los cuales versa son clasificados por Spinoza como soberanos y no como contingentes. El llamado de la utilidad, ya por una vinculación a cosas, ya por una vinculación con causas, es una tendencia que está anclada en las entrañas de la naturaleza humana. El colofón de esa explicación sobre la utilidad es presentada con un sabor de sentencia clásica: "Pero, mientras pretendían mostrar que la Naturaleza no hace nada en vano (esto es, que no sea de utilidad para los hombres), no parecen haber mostrado otra cosa sino que la Naturaleza y los dioses deliran lo mismo que los hombres" ${ }^{\prime 2}$. A Spinoza puede atribuírsele explicaciones arduas sobre dos formas en las que se despliega el sentido de utilidad vinculadas a los prejuicios finalistas: el mesianismo y la imaginación apocalíptica nacen de esa inclinación a ver signos de lo mejor y de los peor en el orden natural. Detrás de esas manifestaciones extremas de la imaginación se mueve un cálculo de la naturaleza humana, una manifestación mistificada del temor y la esperanza, el fetichismo nacido del interés y de la tensión frente a la fortuna. La vida se desarrolla en un contexto de múltiples acontecimientos. No se trata, por tanto, de dar respuestas unívocas y dogmáticas a esos trances. La admisión 
de la inclinación a la utilidad como algo constitutivo de la condición natural del hombre y que alude, en más de un sentido a la astucia, al engaño, la argucia, si se trata de conservar a nuestra naturaleza ${ }^{3}$. Para una moral rígida, los dos ejemplos representarían una apología de la mentira y de las falsas promesas. Sin embargo, Spinoza respondería que en una situación violenta, las argucias son un medio legítimo para liberarse de un acto que amenaza a nuestra naturaleza. Las cosas, que son bienes por los cuales se inclina nuestro sentido de utilidad, no aparecen inicialmente como algo neutral sino como dotadas de un significado inmediato y como portadoras de un peso específico, de mayor o menor densidad afectiva y de un resplandor que inevitablemente despierta al interés. Este temple es el procesamiento que elabora nuestro ser en cada circunstancia en que tiene que enfrentarse a las situaciones vitales, en la medida en que ese procesamiento se somete a la regla básica que nos permite evitar entre las cosas funestas a los males mayores y bienes superiores en lugar de bienes inferiores. Porque están dotadas de significado es que se convierten en bienes que juzgamos a partir de esas dualidades que señala Spinoza en el Apéndice de la primera parte: de esa especie de narcicismo (que en otro tiempo se llamaba "humanismo") o de esa manía derivan perspectivas de las cosas tal y como nos afectan, no tal y como son en sí mismas ${ }^{4}$. El impulso de utilidad no es, en primera instancia, fuente de conocimiento sino de impulsos vitales: se vuelve la medida de nuestros prejuicios más que de nuestros juicios. Las cosas son concebidas como medios que sirven para realizar fines, no causas que explican el orden de las cosas, una suerte de tesis del homo mensura que juzga la constitución de lo individual a partir de la satisfacción de expectativas individuales y no a través del conocimiento de lo necesario. Si dejáramos de considerar a la naturaleza de las cosas bajo la óptica finalista fácilmente se comprendería que las cosas no están hechas a nuestra medida y que no somos sino un elemento más -no el centro- de todo el orden en el que ella está dispuesta. De esa tendencia se deriva el prejuicio según el cual hay un rector personal de la naturaleza, es decir, una providencia que dota e imprime a las cosas el sentido de su uso. Todos sabemos que la obra de Spinoza está avocada a encontrar el principio que explique tanto a los hombres razonables como a los coléricos, a los virtuosos como a los imprudentes, los crédulos y los sutiles. Se trata de una evaluación que determina de manera omnímoda los momentos en que se computan riesgos y beneficios, en todas las situaciones $\mathrm{y}$ en todos los gradientes de la condición humana; esta evaluación, que puede inclinarse por un apetito sórdido tanto como una virtud calificada por la más alta potencia de actuar. El carácter comprehensivo de este concepto desvincula a la ética y a la política de Spinoza de una visión pastoral de la naturaleza humana, porque admite la posibilidad de que un individuo pueda ser tan débil como activo, irreflexivo y lúcido, pues el sentido de la utilidad lo mismo crea las más funestas dicotomías de la imaginación que un poder intelectual que los eliminas. Genera juicios y prejuicios, con la misma vivacidad; impulsa a dos tipos de perspectiva causal que Spinoza identifica o bien con la lógica de los prejuicios generados por la ilusión causal de la finalidad, o bien con la perspectiva de la causa eficiente, es decir, con la perspectiva necesaria de las cosas. La tendencia a la utilidad expresa, en suma, lo más noble y lo más bajo, lo absurdo y lo racional, toma el pulso a lo imaginario e impulsa a lo razonable. De esta inclinación nacen las tendencias deformadoras de la superstición, pero también las pautas más virtuosas del espíritu de la geometría. En la doble condición del sentido de utilidad en el hombre se fundamenta una clase de antropología que se explicita en su perspectiva ética y política. Fundamenta una teoría adecuada del error y confiere a la definición del hombre un punto de partida sólido: la inclinación natural por la utilidad nos impulsa tanto al prejuicio como a la virtud. La falsa definición del hombre -la que nace de 
nuestra relación interesada con las cosas y del desconocimiento de las causas- asigna al alma humana estas licencias: libre albedrío, voluntad, bondad. Un conocimiento adecuado, claro y distinto sólo puede proceder por la aprehensión de la esencia de la cosa y no por determinaciones extrínsecas, pues los prejuicios son el verdadero obstáculo para el conocimiento real del hombre. Que el bien y el mal no se den en la naturaleza sino en un pacto político indica que no se puede tomar a éste como punto de partida; para un pensador "esencialista" no puede tomarse como fundamento de la concepción del hombre algo extrínseco y variable. El concepto de utilidad le permite dar un tratamiento de las cuestiones éticas por encima de las perspectivas más tradicionales en las que el sentido del bien o de los bienes son demasiado restrictivas o demasiado amplias: la utilidad no es un Soberano Bien sino solamente lo que nos permite acceder a los bienes y rechazar los males, en la medida en que se trata de un estado afectivo más que de una idea. La tendencia es algo que está inscrito en la naturaleza del hombre y se despliega en cada situación que implique valoración de riesgos y expectativas. La búsqueda de utilidad no aparece como una reivindicación abstracta de la potencia de actuar sino como una acción que juzga sus resultados y es capaz de ponderar los efectos de ésta. Incluso en el debate contemporáneo todavía se encuentra presente esa eficiencia que se realiza en la maximización y limitación de nuestras acciones ${ }^{6}$.

Un individuo define lo que le es útil antes de tener en cuenta las ordenanzas sociales. Quizá por ello el primer problema de una comunidad política es de corte semántico: se inaugura ávida de seguridad y se abre a la creación de un consenso sobre los bienes que apetece su esperanza y los males que rehúye su temor (Spinoza 15, E. cuarta parte, pr. 37, Esc. 2, p. 210). En el estado de naturaleza nada se da con el nombre de justicia e injusticia, delito o mérito; por tanto, no se puede dar tampoco la idea de castigo o de recompensa que suponen la trasgresión o el sometimiento a la ley. La idea de justicia, tanto como la de bien y de mal, no son algo que se posee naturalmente, pues ésta es instituida por la razón, pero no por nuestras inclinaciones, pues ellas no contienen de entrada una afección social como es la justicia. ¿Qué implicaciones tiene el concepto de utilidad cuando Spinoza quiere explicar un paso calculado hacia la seguridad individual? El primado del principio de utilidad expresa la entronización de los bienes y los males que nacen de nuestro contacto afectivo, ilusorio y puramente externo con las cosas, pero también contiene la afección de la seguridad que empieza a relativizar el valor absoluto de los deseos. La ruta de la seguridad pasa por el acotamiento de lo ilimitado ${ }^{7}$. Donde los derechos de los individuos son inconmensurables, los cálculos de la vida son más pródigos, las decisiones son más arriesgadas y la seguridad mínima: tener derechos a tope es también tener menos seguridad. La disposición a ponderar se nos hace presente en todo momento en que precisemos de evaluar los riegos y ventajas de una decisión. La naturaleza humana se despliega en las situaciones en que nos asaltan las circunstancias de una manera apremiante, pues obliga a que los individuos tanteen permanentemente decisiones que maximizan y minimizan los impactos en nuestra vida. La naturaleza humana obra a través de los afectos primarios que computan los bienes y los males implicados en una deliberación comparativa operada por el temor y la esperanza. En efecto, para que los afectos hagan este cálculo, es preciso que los bienes y los males de la situación sean conmensurables y, por tanto, ofrezcan, así sea de manera aparente, un criterio de selección ${ }^{8}$. La realidad finita es de conmensurables y con mensuradores; en la Ética se yuxtapone el tema de fundamentación del infinito -la noción de causa sui- con la clara intención de contrastarlo con una realidad determinada, dependiente y sometida a la exigencia de contrastar la relación máximo-mínimo. Siendo una determinación de la 
finitud, entiende que esta disposición al cálculo no es una conquista de la civilización sino una herramienta de la naturaleza humana; no es algo que se aprende sino algo con lo que se nace. Un individuo que, por naturaleza, está sujeto a riesgos, necesariamente tantea y estudia la ruta que más le favorece y menos lo expone a encuentros tristes. Cuando Spinoza propone la definición de "cosa finita" siempre plantea un criterio matemático para identificarlas, a saber, que siempre son concebibles en función del criterio de "mayor o menor que": la utilidad, que siempre se despliega en el orden de las cosas finitas, siempre revela esta consistencia que tienen los bienes que se mueven en el orden de las apariencias y de la negatividad. A través de la tristeza descubrimos el dominio de la finitud, la ficción de la libertad bárbara y el derecho absolutos y, desde luego, la violencia que entrañan; a través de la tristeza descubrimos el dominio de la finitud y la esperanzas que se tiene que suministrar un ser que no es causa sui, la disposición a buscar una esfera de bienes más estabilizados y garantizados por el derecho. El estado natural despliega la ilusión de la soberanía absoluta del individuo, tanto como su disposición a la melancolía.

Alejado de la esfera económica en la que se planteó por muchos filósofos, el "utilitarismo" de Spinoza no estaba vinculado al "egoísmo posesivo" que soportó a la visión economicista de este principio: el pensamiento spinoziano no problematiza a la angustia por el futuro y la tendencia a atenuarlo con las certezas que da el "derecho a propiedad". Incluso si se trata de la esperanza como algo unido al futuro, la propiedad no puede considerarse como un sustrato de la fortitudo animi. Por citar un ejemplo, la angustia que Locke descubrió frente al futuro la resolvió con la certeza de los bolsillos rebosantes de dinero y con abundantes títulos de propiedad. Tampoco se trata de la deliberación de un consumidor de productos o de un productor que calcula la relación costo-beneficio, tal y como la economía clásica lo concebía. La escala subjetiva de los gustos no coincide con la determinación necesaria de las decisiones vitales. En esta escala no se mueve un consumidor de mercancías sino una determinación de la naturaleza, una verdad eterna precede al mercado. Aunque la utilidad es una medida de cálculo, la realidad más primaria de un modo o de un ser finito no se presenta como una mercancía sino como algo que confirma o niega al ser propio. A diferencia de los utilitaristas clásicos, nuestro contacto con los bienes no son en sí mismos un motivo de placer o tristeza: el gozo y la tristeza son indicadores que manifiestan nuestro estado de potencia, el vínculo más directo con nuestro ser. Así como el panóptico es el Cristo pantocrátor de la vigilancia, (o, para decirlo como Foucault, una "tecnología de poder"), los cálculos de placer son para Bentham la expresión de una redención creada por el consumo y su regla universal "el mayor placer para el mayor número". Para éste, la felicidad es un parámetro, para Spinoza el gozo es un gradiente o un estado de la potencia de $\operatorname{actuar}^{10}$.

\section{Las dudas de la acción: simiente política del temor y la esperanza.}

"Por consiguiente, todo cuanto un hombre, considerado bajo el imperio de la naturaleza, estime que le es útil, ya le guíe la razón, ya el ímpetu de la pasión, tiene el máximo derecho a desearlo y le es lícito apoderarse de ello de cualquier forma, ya sea por la fuerza, el engaño, las súplicas o el medio que le resulte más fácil; y puede, por tanto, tener por enemigos a quien intente impedirle que satisfaga su deseo".

Tratado Teológico-Político, Cap. XVI, I.

El cálculo de utilidad es un dispositivo que le quita el carácter neutral a los bienes y los convierte en el objeto de un interés desplegado con la eficacia de las afecciones más originales de nuestra naturaleza. Se trata de un movimiento oscilatorio de esas pasiones primitivas del estado natural. En efecto, nuestros cálculos pertenecen al imperio de la fortuna y 
la sede en la que realiza este cómputo también habita la duda, una operación de tipo moral que, para Spinoza, está ligada a las circunstancias, es decir, a todo aquello que no depende de nuestra naturaleza. Éstos calibran y descifran los contextos de acción a través del miedo y la esperanza: el descubrimiento del mundo del entorno no es una experiencia neutral sino un acto que diseña una estrategia defensiva y otra de prospectiva. No hay nada objetivo ni metafísico en el primero y, en el segundo, no se advierte ninguna promesa escatológica: Animi fluctuatio et dubitatio inter se differunt nisi secundum majus et minus (Spinoza 15, Eth. Pars Tertia, p. XVII, Esc.). El reino de la duda es, como el dominio de las cosas finitas, el del más y del menos, la ponderación comparativa. Si el objeto de la duda es, para Descartes, -la fiabilidad de los sentidos, la indistinción entre sueño y vigilia- la única opción para la duda spinoziana radica en la acción misma. ¿Se actúa como se duda y se duda como se actúa? El temor y la esperanza posicionan a la duda antes que la acción, porque, aún eligiendo el mayor de entre dos bienes y el menor de entre dos males, los cálculos operados en esta esfera de incertidumbre se ejercen sobre la apariencia de las cosas. Sólo un juicio en el que se parte del conocimiento de las cosas tal y como son en sí mismas y no un juicio de las cosas tal y como nos afectan, puede controlar los resultados de la acción y, con ello, eliminar toda sombra de duda. El cálculo de utilidad no parte de un conocimiento puntual de los resultados de la acción sino de una impresión ponderativa: la esperanza no garantiza y, por eso, forma parte de las afecciones débiles; el temor puede hacer también un mal cálculo, porque puede sobredimensionar los alcances del objeto temido y, acompañados con esa tristeza, declinar a los temores hasta el terreno de las supersticiones. Por consecuencia, se puede decir que la certidumbre de la acción sólo puede provenir de la virtud misma; porque la virtud no depende de la fortuna, los resultados de la acción siempre se mueven en el orden de la fortitudo animi. Si bien la esperanza puede ser premiada con la fortuna, el miedo no quiere recompensas del objeto de su temor sino, en todo caso, alejarlo. Por ello, para Spinoza la duda no es el fruto de la acción sino su simiente. Las herramientas que poseen para controlar los efectos de la acción tienen la misma debilidad que sus fuentes: el temor y la esperanza ponderan, pero no determinan. Consternación y admiración satisfacen y castigan esas operaciones desplegadas sobre el horizonte de la duda y el mero contacto ilusorio que tiene el interesse con el orden de las cosas.

Las pasiones instrumentales se distinguen de las virtudes puras en función del origen de ambas: las primeras son efectos de la imaginación y, las segundas, de la determinación de nuestra propia naturaleza, la conquista activa de lo que somos. Spinoza está lejos de colocar a la esperanza en el rango de virtud; la instala en la línea de las primeras, es decir, aquellas que están vocacionalmente determinadas por la causa eficiente y por esas afecciones que sirven a la evaluación de los bienes futuros. Por su parte, el temor es una pasión que resiste a lo peor, se precipita desde los caminos de la tristeza, pero evita el deterioro de un sujeto amenazado por sus enemigos reales y conjeturales ${ }^{11}$. Se trata de dos polos pasionales que siempre hacen que nuestros actos se inclinen de una determinada manera. Esperanza por un bien mayor y miedo por un mal mayor. Estas dos afecciones humanas están instaladas en el centro de nuestra naturaleza: en cada acto en que las circunstancias nos obligan a ponderar nuestras acciones, el miedo y la esperanza se mueven en el mismo escenario. No dan "infalibilidad" a nuestras acciones, porque no son virtudes, pero, a cambio de eso, confieren a nuestros intereses la flexibilidad necesaria para esquivar, atraer, desviar, acometer, proyectar y sortear. Las dudas generadas por la acción del temor y la esperanza no son resueltas sino por toda la conversión del alma a las cosas eternas, como sugiere la Ética. Mientras tanto, el temor y la esperanza, que se mueven en los registros 
más bajos de la potencia de actuar, tienen que resolver el significado de las cosas antes del advenimiento de la virtud y de la verdadera libertad: estas afecciones constituyen a las dudas de la acción cuando se despliega $s u b$ specie durationis. Aquéllas siempre manan de la fuente del tiempo; los vuelcos y oscilaciones de la fortuna no pueden ofrecer constancia.

El temor es una pasión que prevé: es una respuesta de nuestra naturaleza ante la proximidad de lo peor y la necesidad de alejarlo. La imperfección del temor no radica en que prevea sino en que puede asociarse a la imaginación e inventar peligros: la melancolía es una de las formas en que el miedo se apodera del alma y hace que nuestro sentido de utilidad tema catástrofes, es la huella específica de la impotencia, la ausencia de toda comprensión y de la fortaleza de la imaginación (Spinoza 15, Eth. Pars Tertia, p. XXXIX, Esc.) ${ }^{12}$. Asimismo, el miedo es un cálculo de la ignorancia. Los males que imagina el miedo son inferiores a los que una ocasión real ofrece, surge como respuesta pasiva frente a la adversidad y guía a un sentido de utilidad que no está dotado de suficiente fuerza para la resistencia. La idea de que Dios está constituido por una voluntad absoluta es el fundamento del estupor (Spinoza 15, Eth. Pars Prima, Appendix: Iignorantiae Asylum). Sin embargo, a pesar de que el temor es una pasión, el sentido de utilidad que alberga en su lectura de las circunstancias, puede también fincarse sobre situaciones reales, es decir, sobre peligros inminentes. La pasión específica a la que se adscribe el temor es a la tristeza, pero, paradójicamente, en tanto que instrumento de evaluación de la utilidad quiere evitar a una tristeza mayor. ¿Cuáles serían las tendencias propias de la esperanza en tanto que pasión que está al acecho de los bienes futuros? Es el entusiasmo pasional sobre el porvenir, la promesa de los bienes. El pathos de la esperanza es constitutivo de la naturaleza humana y, en esa medida, nos determina a adoptar la ruta de la afirmación. Estando al margen de una forma activa de virtud, arroja a los individuos a la antesala del poder individual y social. No habría para Spinoza una docta spes que encamina al hombre a la gloria, a la trascendencia, a la salvación religiosa ${ }^{13}$. Más ignorante que docta, la esperanza es una afección que acecha lo que no conoce, y, más aún, esa zona que no está iluminada por la razón es pródiga en ilusiones: mientras más se teme, más se espera. El tamaño del cielo de la esperanza es proporcionalmente inverso al infierno que teme. En la medida en que la esperanza spinoziana no es trascendental, ésta no tiene un contenido escatológico. Todo lo contrario, advierte que en toda forma religiosa de la esperanza se traslapa una superstición sobre la perfección humana. En lugar de esa perfección ficticia, postula una perfección que está al alcance del hombre y de su salvación intramundana ${ }^{14}$. Por tanto, los caminos de la esperanza también se mueven en el horizonte de la naturaleza. Esta expectativa está determinada por nuestra tendencia a la perfección, aunque nazca dubitativa e incierta. Si bien Spinoza rechaza el concepto de duda en el ámbito cognitivo, en relación a la esperanza se introduce como una condición propia de la acción y la incertidumbre sobre nuestra eficiencia ${ }^{15}$. Incluso nuestras pasiones están determinadas a elegir a favor de todo lo activo y se consuman anulándose en el paso a la perfección virtuosa. La esperanza es el paso decisivo que dan los individuos hacia la constitución de lo social como una conquista de perfección tanto individual como colectiva. ¿Cómo juzga Spinoza, desde la perspectiva de la naturaleza humana, la relación entre los intereses personales y los de los otros? Ningún individuo tiene dudas en su inclinación inmediata por sus propios intereses: el principio de eficacia siempre obliga a la elección de sí mismo. El pensamiento de Spinoza está lejos de considerar al altruismo como una disposición natural; el interesse, una zona en la que se confrontan el pensamiento de Spinoza con el de Lévinas, es, en primer término, una vocación por la continuidad de la vida $\mathrm{y}$, al mismo tiempo, una forma "de ser en el mundo" 16 . 
Se entiende que el pacto de muchos individuos quiera sustituir a la fuerza que los amenaza por derechos equitativos. Sin embargo, Spinoza no habla de un igualitarismo obtuso, reducido a una homogeneidad originada por el temor y la esperanza: los derechos equitativos solamente tienen sentido si sirven para aumentar los intereses de los individuos. La homogeneidad del temor y la esperanza sería temible si no representa solamente un tránsito hacia algo superior a esas manifestaciones de las fluctuaciones del ánimo. A tal punto lleva ese razonamiento que la conservación y el aumento de los intereses no deja de ser una razón para admitir su necesidad; vista así, la sujeción a los límites de los derechos impuestos por la ciudad son, en realidad, útiles para afianzar los bienes propios:"Pero la naturaleza humana es de tal índole, que cada uno busca con sumo ardor su utilidad personal y estima que los derechos más equitativos son los necesarios para conservar y aumentar sus intereses, mientras que sólo defiende la causa ajena en la medida en que, de esa forma, afianza su propio bien".(Spinoza 17, TP, Cap. VII, 4, p. 154). Esta transición entre el máximo derecho y los derechos individuales acotados es la que explica la institución de la justicia como una forma oblicua y más eficiente de consagrarse a los intereses individuales. La ciudad no es la suma de las renuncias de los derechos naturales sino una asociación de potencias dirigidas a la construcción de un clima de seguridad y, más tarde, de libertad y solidaridad. A partir de la seguridad, la potencia de actuar de la ciudad se constituye hacia la reforma de sí misma ${ }^{17}$. La asamblea democrática representa a todos los poderes entendidos como la manifestación de la voluntad de consenso. Antes de ser determinado por la razón el derecho natural está determinado por otra fuerza que es previa a ella; no todos están dotados de razón pero si todos están dotados de derechos naturales: antes de obedecer a la razón, el hombre obedece a sus impulsos.

La naturaleza nada prohíbe en la defensa del deseo, el apetito y en todo aquello que parezca útil a los hombres. La noción de prohibición no existe donde no hay una asociación. La amplitud de los sujetos de este derecho le permite incluir bajo este concepto no sólo temas de carácter político sino que permite replantear temas de carácter ético, físico y ontológico, pero también sus paradojas y sus límites: aunque los derechos naturales sean absolutos, no son deseables, ni virtuosos ni están fundados en una libertad superior. El derecho natural, derecho sin jueces, tribunales, acusados o acusadores, sin castigos y sin méritos, consiste en una fundamentación de todo aquello hacia lo cual estamos determinados. La determinación comprendida como quae ex sola suae naturae necesitate no consistiría sino en los dictados que siguen todos los seres respecto a su propia naturaleza. En un pensamiento que ha excluido al azar del orden de la naturaleza, un orden causal necesario es sinónimo de racionalidad. Racionalidad sería aquí entendido como "de conformidad con natura".

La socialización del temor y de la esperanza representa, en realidad, el paso político más fundamental: antes que una deliberación deseable, tenemos una asociación motivada por los idénticos miedos y por esperanzas comunes, es decir, sometemos nuestros cálculos a afecciones comunes. Cuando están en juego los intereses propios y los ajenos todo mundo se inclina sin reticencia alguna por los propios. El concierto de los temores no abandona el culto al interés personal y solamente consistiría en una forma oblicua de egoísmo; la lógica bajo la cual un individuo percibe la necesidad de la ciudad no deja de ser un estricto cálculo individual. Un Hidalgo no puede existir en un lugar dominado por la especulación y el cálculo sobre los mejores rendimientos de la acción: la selva no reconoce títulos nobiliarios pero sí ofrece muchas ilustraciones de cómo procede la naturaleza humana, ahí donde todavía no hay límites. La esfera de la prerracionalidad en la que Spinoza investiga las razón suficiente de la ciudad no podría encontrar a los propietarios deliberando apacible, universal y racionalmente sobre optima politia, tomando el té y hablando caballerosamente sobre las cláusulas de un contrato ${ }^{18}$. La noción 
de justicia se introduciría necesariamente como posición judicativa, es decir, en ella intervienen opiniones y no la naturaleza. A diferencia del derecho instituido humanamente, no se puede derogar, modificar: es inmutable, eterno y gobierna no sólo los actos de los hombres sino a todas las cosas finitas. La noción spinozista del derecho natural está concebida como una condición previa a la fundación de la ciudad. Es por ello que Spinoza trata de ordenar la investigación acerca de sus fundamentos, antes del nacimiento del consensus comunis, el pudor que inventa un sentido de lo político y la capacidad de hablar uno al otro. Lo que reivindica el derecho natural es la existencia de una fuerza no dirigida específicamente a algún lado. Examinado así, no existe lo moralmente correcto, lo justo y lo bueno. La visión que Spinoza posee de la justicia es sociocéntrica, secular y racionalizante; la de sus antagonistas, señaladamente Leibniz, es teocéntrica, autoritaria y moralizante. La polidikea (la oposición al concepto teodikea), la sociedad inventada por afección a la justicia, es una de las formas de secularización del horizonte valorativo más básico, una de las conquistas del consenso.

\section{La deducción del máximo derecho ${ }^{19}$}

"De lo anterior se sigue que el derecho e institución de la naturaleza, bajo el cual todos nacen y viven la mayor parte de su vida, no prohíbe nada más que lo que nadie desea y nadie puede; pero no se opone a las riñas, ni a los odios, ni a la ira, ni al engaño, ni absolutamente a nada que aconseje el apetito. Nada extraño, ya que la naturaleza no está confinada a leyes de la razón humana, que tan sólo miran a la verdadera utilidad del hombre y a su conservación, sino que implica infinitas otras, que abarcan el orden eterno de toda la naturaleza, de la que el hombre es una partícula, y por cuya necesidad todos los individuos son determinados a existir y obrar de cierta manera". TTP, Cap. XVI, I.

En el estado natural, ser un individuo consiste en entrar en choque con fuerzas de individuos y tener fuerza significa medir fuerzas: todo es oposición y choque. Por tanto, en el estado natural la inclinación por la utilidad no reconoce ningún parámetro de bien y de mal, pues todo lo que satisface a la utilidad nace de la ausencia de todo criterio para calificar a las inclinaciones de un individuo. Spinoza hace de la tendencia hacia la utilidad un reconocimiento explícito de la individualidad que está centrada en satisfacer sus propias expectativas, que la naturaleza misma establece esas leyes que, en primer instancia, son las de la preservación de la propia constitución como el primer bien de los individuos; las múltiples nociones de bien que poseen los individuos son conflictivas. Spinoza se percata que ahí donde hay un máximo de derecho individual también hay un máximo de conflicto; en efecto, si los individuos nacen dotados de un derecho ilimitado, los conflictos con los otros también lo son. Discordia y máximo derecho son correlatos. Sin embargo, Spinoza matizará esta tesis de la siguiente manera: la necesidad de limitar a los máximos derechos tiene por objeto a la seguridad que alcanzarán los individuos en una situación en que todos debilitan a sus derechos. La razón por la cual Spinoza deja intacto al máximo derecho a pensar es porque, justamente, no amenaza a la seguridad de los otros y porque maximiza toda búsqueda de utilidad en un individuo.

La politización del temor y de la esperanza son los sustentos pasivos de la majestad del Estado, es decir, del orden político más elemental. Por tanto, los enemigos de éste son aquellos sujetos que son autónomos en sus temores y sus esperanzas, pues sus objetos pasionales son divergentes como temibles: en el pánico, podría haberlo dicho Elias Canetti, se forma la primera asociación en el terror ${ }^{20}$. De entrada, la fortaleza de una sociedad está en las pasiones que puede compartir y a partir de las cuales puede calcular el mayor de los bienes y evitar al mayor de los males. Un verdadero estado de hostilidad se reconoce como la ruptura de un orden en que los temores y las esperanzas no suscitan ninguna identificación y ningún compromiso de caridad y justicia. De ahí que la sustitución del derecho civil por el 
derecho de guerra sea también una ruptura de las afecciones sociales más fundamentales: el derecho de guerra se impone como dominado por un retorno a los significados puramente individuales del temor y de la esperanza, su absoluta autonomía. En lo fundamental, Schiller tiene razón: estar suelto no quiere decir estar libre. La república se funda coligando la suerte de los demás a mí propia suerte, estableciendo un entramado de relaciones, palabras y afectos. La libertad es un concierto y un tejido de vínculos.

El estado natural se remite a un momento en que los individuos poseen el máximo derecho a todo. Es esta perspectiva spinoziana del derecho como algo que no tiene ningún límite, salvo los del propio poder de los individuos. Eso indica, por un lado, que éstos pueden aspirar a todo lo que el apetito les insinúe, desear todo lo que la imaginación les ofrezca; el máximo derecho a todo no tiene ni límites morales, religiosos o jurídicos, porque se presenta en el curso de las inclinaciones que no tienen la resistencia esas fuentes de los escrúpulos y emprende su búsqueda de bienes sin ningún obstáculo, salvo el de los otros que pueden apetecer el mismo bien. En el entramado del derecho natural, ser una criatura consiste en desear todo lo que nuestro poder logra realizar. Un individuo finito que hace coincidir derecho y poder a la fuerza: esa conjunción se impone por medio de todos los recursos concebibles de los que puede disponer, al margen de la justicia, la piedad y la conciencia. Spinoza insiste: el límite de nuestro derecho es el límite de nuestro poder y de nuestro deseo. No tenemos, en absoluto, derecho a nada que no hayamos conquistado por vía de nuestra propia potencia. La idea de límite o de contracción prohibitiva del deseo tendría aquí un sentido positivo: aquello que implica nuestra propia negación debe ser limitado, todo lo que signifique expansión y excitación de la potencia debe ser estimulado.

El individuo está privado de todo parámetro externo que le indique que está obrando bien o mal y, en esa medida, el deseo y el poder se vuelven medida del derecho y de lo útil. Se impone así la perspectiva del deseo y del poder como criterios inmanentes de valoración ${ }^{21}$; si bien hay una muchedumbre de cosas que rebasan a nuestra potencia de actuar hay también muchos elementos que permiten su conservación, habida cuenta que la naturaleza suministra los elementos que hacen peligrar nuestra existencia pero también los medios para evitarlos: esos elementos de la perseverancia son a los que tiene derecho irrestricto el individuo finito para conservarse. Con todos estos arreos conceptuales, Spinoza renuncia a la fundamentación metafísica de las normas sociales y a las fórmulas platónicas de valoración. El carácter ilimitado de este derecho consiste en no estar sujetos a ninguna determinación sobre el orden de lo justo o de lo injusto, pues no hay ni justicia ni moral donde no se establecen los límites de la acción humana. Tenemos derecho a materializar a todas nuestras inclinaciones de utilidad, aunque nuestra fuerza para consumarlas sea limitada.

Por un lado, Spinoza asume que la instancia fundamental que gobierna a todas nuestras afecciones no es una institución humana. ¿Se trata de un tipo de derecho que está por encima del arbitrio humano y que se presenta como la primera instancia a la que se apela para comprender a nuestros actos? El orden eterno al que sujeta al hombre está por encima de cualquier arbitrariedad y asume un carácter irrevocable, a tal punto que no elegimos ser de esta o aquella manera, sino que estamos compelidos por ella en virtud de su necesidad. Spinoza se desmarca de las concepciones iusnaturalistas clásicas cuando deja de sostener que en la definición de los derechos no está involucrada una acción humana. El orden eterno al que apela permanece intacto por cualquier voluntad humana. La ética fundamentada en los deberes tiene una procedencia trascendental, es decir, responde a principios y no a inclinaciones, como nos lo ha hecho saber $\mathrm{Kant}^{22}$. Una fundamentación inmanentista, por el contrario, está sostenida 
en todos los dispositivos para la acción eficiente y lo que ésta demanda de manera inmediata: la perseverancia en el ser. Lo que sostiene es que los deberes, o todas las formas derivadas de obligación como los pactos, las promesas, los compromisos, si demandan conductas que están por encima de nuestra naturaleza, es legítimo no cumplirlos. El criterio último de decisión siempre está determinado por la naturaleza y a ella se remiten todos los argumentos para mantener o rechazar promesas que atentan contra nuestro propio interés. En ese sentido, la ética de Spinoza no está centrada en la lógica de los deberes "que son amables en sí mismos"; no es que Spinoza sostenga que los deberes son por sí mismos necesarios, sino que hay imperativos más primarios que los que responden a una fuente trascendental de la moral. En la medida en que no hay deberes es que Spinoza concibe a los individuos como exclusivamente dirigidos a cumplir con su interés, sin ninguna consideración acerca de lo bueno y lo malo. La naturaleza no llama a cumplir deberes porque no hay en ella ningún sentido de bien; en términos absolutos o en términos relativos, el bien es un producto de la civilización y, en no menor medida, como lo dijo Rousseau, el mal también lo es. Ni siquiera se puede decir que el estado natural es la perfecta expresión de la ausencia de Dios y de la consiguiente validez de todo. Spinoza concibe que la sociedad política nazca al unísono con las religiones y que todo lo que les precede es una compleja esfera de intereses encontrados, de conflictos entre fuerzas y de inseguridad. La religión es un esfuerzo por disciplinar a través del temor y una promesa ultramundana de la esperanza. Por ello, se constituye como eje de la creación de la noción de bien y de mal. En muchos sentidos, la política es una continuación de la religión; en otros tantos, la política es la suplantación de la misma, la secularización del bien y del mal, la invención de un sentido inmanente de la justicia. Sin ley y sin religión, no hay injuria ni pecado. De ahí que a menudo relacione la "edad profética" con el surgimiento del Estado de
Israel y haga coincidir la ley política con la ley religiosa: política y profecía son dos encarnaciones convergentes y divergentes del temor y la esperanza (Spinoza 16, TTP, Cap. XVI, V, p. 349). En efecto, todo parece indicar que nuestra noción del deber se forma cuando se nos exige lealtad a principios, a nociones de bien, a imperativos éticos y políticos. En el estado natural, Dios es un concepto vacío. Libre de todos esos gravámenes, un individuo se dedica a realizar sus intereses. La “desorientación” propia del estado natural se expresa en el vacío de religión y, por el otro lado, de una libertad con la que todo individuo nace al mundo. Esta situación es la que hace que la naturaleza se entienda como un espacio fértil para la búsqueda de utilidad: la libertad que no reconoce amos y la ausencia de una religión que someta a los individuos a la obediencia.

\section{Todo el poder para el deseo}

El análisis spinoziano del paso del estado natural al estado social consiste en la acotación del máximo derecho a todo de los individuos. En efecto, ese análisis está orientado por la idea según la cual el hombre actúa siempre bajo la determinación de leyes, ya sean de orden natural o de origen humano. Las leyes naturales no son instrumento para acotar los derechos sino, todo lo contrario, para orientarlo hacia el máximo posible. En efecto, la ley natural les impone a los individuos la irrevocable necesidad de orientar al máximo sus esfuerzos por conquistar todo lo que la naturaleza les ofrece. Las leyes sancionadas humanamente operan al contrario: limitan y obligan. Se trata de un tipo de prescripciones que impone límites a las acciones que pueden ser objeto de una sanción. En la naturaleza no se da ninguna ley que limite el deseo desbordado de la individualidad salvaje: ese contenido sin continente inunda temerariamente todo lo que le rodea y amenaza incluso a su propio autor. El continente y la forma de los deseos 
es, debemos decirlo, una obra de la comunidad política: el estado civil forja un lugar en los que los aloja y les da una orientación en la que terminan de ser una fuente de conflicto con los otros individuos.

Imponer límites no consiste en una abdicación de nuestra naturaleza a favor de la formación de una vida en común; incluso se puede decir que esa renuncia es, de una manera u otra, una afirmación de nuestro ser consistente en el descubrimiento de la esfera social. En este punto se le plantean a Spinoza algunos problemas. ¿Se levanta un imperio dentro de otro imperio cuando el hombre se decide a vivir asociado? ¿Se rompe con la necesidad de la naturaleza cuando el hombre se da leyes producto de su intelecto? ¿La vida política se abre a lo posible, una noción rechazada hacia el final de la primera parte de la Ética, cuando construye instrumentos para su convivencia social? A todo eso, Spinoza responde de la siguiente manera: "que los hombres cedan o se vean forzados a ceder algo de sus derecho, que tienen por naturaleza, y se constriñan a cierto modo de vida, depende del arbitrio humano" (Spinoza 16, TTP, Cap IV, I, p. 136). Sin embargo, no cesa de considerar a la naturaleza como el horizonte del cual dependen las leyes humanas: incluso todo aquello que está concebido ad usum vitae depende de una potencia del hombre, esto es, de una potencia de la naturaleza total. El arbitrio humano sirve a las cosas de la vida y no puede asumirse como una ley superior a la de la naturaleza, pues se trata de un tipo de normas que están destinadas exclusivamente al gobierno de las cosas humanas; sería tan absurdo como decir que una ley humana puede someter a la ley del movimiento y del reposo, una ley que posee carácter absoluto en relación a los cuerpos. ¿Es la duda al estado natural lo que la razón es al estado civil? Difícilmente Spinoza plantearía la cuestión de esa manera, pues la sociedad no puede abolir las contingencias sino sólo identificar los objetos del temor y de la esperanza. En efecto securitas significa el desvanecimiento de las dudas (Spinoza 15, Eth. Pars Tertia,
Affectuum Definitiones, XV), pero también es la imperii virtus (Spinoza 17, Tractatus politicus I, VII). El estado civil no es un régimen epistémico sino un orden fundado en la lealtad de todos hacia todos: la fundación de la virtud del Estado abre un compás de certeza ético-política, no una certeza intelectual; la seguridad es, en cierto sentido, una forma de debilitar el imperio de el temor y la esperanza, la primera sólida conquista del derecho de todos a todo. Pero la seguridad expresa una conquista del cálculo social, no del individual: con la seguridad la acción individual no se vuelve más eficiente, sino que, en todo caso, permite que los individuos avancen hacia la fortaleza del ánimo. En efecto, Spinoza concibe a la asociación como algo determinado a conquistar todo aquello a lo que tenía un individuo derecho de una manera tal que el sujeto del derecho se transforme. Si el sujeto de los máximos derechos es el individuo que vive en estado natural -sin ley y sin Dios- el sujeto del derecho civil será el cuerpo social considerado como un todo; aquí la relación frente al máximo derecho se invierte: todos tienen derecho a todo y los individuos participan en ese todo como miembros de un cuerpo, y no como individuos que no están sujetos a ninguna ley. En efecto, la idea spinoziana de Imperium consiste una sujeción de todos a la voluntad de todos y le confiere al consenso un carácter vinculante e interdependiente.

Con la irrupción de la vida social los apetitos no desaparecen sino que se transfiguran; en efecto, nada que sea natural puede desaparecer en el horizonte del Estado, lo único que aparece son las restricciones en contra de la injuria y la contumacia. Si el estado natural es la ordenanza a la que se ajusta la vida individual, la ley positiva es la consumación de un valor humano. Más aún: el carácter humano de la ley radica en que nos hace descubrir la relatividad social las pasiones a favor de un descubrimiento de los otros individuos, más allá de la amenaza y de la confrontación de fuerzas e intereses: la ley humana revela, pues a la justicia como un estado 
en el que las pretensiones individuales se sujetan a una institución razonable y llama a deponer a la fuerza como medida del derecho máximo. El otro aspecto de la tendencia a la utilidad se remite al ámbito de la ética y llega a comprender a la razón como un poder realizador de la máxima utilidad, es decir, en virtud y en actividad. La prueba de la continuidad entre el estado natural y la sociedad política la exhibe Spinoza en la tendencia a la utilidad que permanece intacta, pero individualmente limitada y socialmente radicalizada; los individuos coligados por la ley son los que apetecen, se inclinan a todo lo por lo que están determinados. El concepto de utilidad juega un papel tanto individual como social y le confiere a los derechos, en uno y otro registro de la vida humana, un carácter ilimitado: una sociedad prudente, es decir, orientada por el temor y la esperanza, procede de igual manera a la que un individuo procede en el estado de naturaleza, calculando sus decisiones, alejando los peligros en contra del Estado y su seguridad y, al mismo tiempo, adoptando para sí los máximos bienes posibles. Todos los atributos que tiene un individuo en el estado de naturaleza adquieren una escala social y, al frente de ellos, está el sentido de utilidad.

$$
* * *
$$

Hay dos sujetos del “derecho máximo a todo”. Por un lado tenemos a los individuos que en el estado natural, sin arbitraje y sin límite alguno, tienden a buscar todo lo que su particular disposición le dicta como útil. Por otro lado, tenemos la encarnación propiamente colectiva del máximo derecho a todo en la que este derecho se despliega en el ámbito de la vida social. Spinoza sostiene que todas las tendencias de la naturaleza humana son eternas y no pasan por nada que los limite: el nacimiento del consenso no los elimina sino que los transfigura en un objeto de la sociedad que, en su conjunto, adopta el papel que un individuo tenía en el estado natural. Para
Spinoza, la primera figura de racionalidad que se asoma en una multitud, después de fijar los contenidos de lo que se debe temer y esperar, es esta actividad creada por las palabras e ideas intercambiadas con benevolencia. Los estudiosos del pensamiento republicano nos han transmitido la tesis según la cual la república es un paraíso de la virtud y, sin duda Spinoza participa de esta convicción. Sin embargo, su republicanismo no niega los orígenes poco virtuosos de la república: el temor y la esperanza no son la negación absoluta de la virtud sino solamente un pasaje hacia la virtud del imperium. Si bien la manifestación más degenerada del temor es el terror, ese resorte pasional de las tiranías, para Spinoza no es más que un puente hacia la autoconstitución de la multitud.

Por un lado, la Ética analiza las elaboraciones subjetivas que tiene el sentido de utilidad y desemboca en una denuncia de la imaginación que le provee al hombre muchos de sus prejuicios y de sus apetitos; el plano en que analiza la tendencia a la utilidad podría adquirir el título de antropología de las disposiciones del hombre y se dispone a estudiar a nivel tanto individual como colectivo las dicotomías propias de la tendencia de la utilidad. Cuando Spinoza sostiene que la tendencia hacia la utilidad es natural en el hombre, sostiene con ello que nunca se puede eliminar. En efecto, si algo es natural no puede ser borrado, como si el hombre accediera a un espacio trascendental cuando elimina o atenúa sus inclinaciones. Spinoza no quiere trascendencia sino "reformar a la naturaleza humana", y eso quiere decir que no pretende ir más allá de sus límites. La ciudad, en ese tenor, es una tentativa de reforma, pero con ella no se crea de una zona de trascendencia que sobrevuela a los impulsos y a las pasiones. Retiene, por tanto, todas las inclinaciones que el individuo posee, e incluso las consuma de una manera radical: no es la culminación de esa reforma, pero en ella se definen todos los instrumentos que una multitud posee para empalmar el interés multitudinario con el interés individual. 
Los individuos retienen su naturaleza y se someten al cuidado que les ofrece al renunciar a hacer daño a los demás tanto como a sí mismos. Con esta declinación los lobos se liman las garras y los colmillos, doblegan a sus instintos y les nace el horizonte de una zona ilimitada del derecho natural, la libertas philosophandi. La prueba más fehaciente del culto a la utilidad propia es la acumulación de los años con la determinación de haberse inclinado muchas veces por sí mismo. Aunque los individuos se sometan a la enmienda de su naturaleza formando parte de una ciudad, no entran a ella a formar mutilando su naturaleza sino orientándola hacia un espacio en el que puede saber con certeza lo que puede esperar de sí mismo y de los otros. El "utilitarismo" se desplaza del egoísmo hacia la realización de la virtud, es decir, apunta hacia la ética como superación y consumación de la odisea individual y social. Decir "soberano bien" o concebir cualquier clase de bien, por polémico que éste sea, siempre implica entenderlos como útiles, pero no como conceptos. De ahí que Spinoza nunca llegue a decir que el "mal" o lo "malo" sean definidos por lo útil, sino, todo lo contrario, es lo que carece de utilidad. En un caso, el del ingenio, el "criterio" lo establecen los individuos; en el otro, el criterio de utilidad lo aporta una comunidad política, en este sentido, la utilidad es una de las formas de nombrar al bien común. Uno y otro establecen pautas de poder o de impotencia: sólo el soberano bien, el que puede articular a la diversidad individual, puede generar elementos que le den móviles a una asociación política.

La multitud reina sobre sus derechos y se ocupa en expandirlos, porque si en algo tiene significado la conjunción entre derecho y deseo, es en la expansión de los derechos. La expresión "el deseo al poder" se justificaría en ese orden fundado por la soberanía popular que interviene en el descubrimiento de lo que puede. El deseo como medida del derecho de la multitud expresa, en sí misma, el desplazamiento del absolutismo y consagra a un nuevo poder constituyente. La asociación no consiste en la eliminación del máximo derecho sino en su apropiación concertada: a partir de ese momento, los desiderata pasan a formar parte de un sujeto que se compone como una agencia desiderativa

\section{ON TRANSFIGURATION OF THE HIGHEST RIGHT TO EVERYTHING: FEAR, HOPE AND CALCULATION OF UTILITY}

Abstract: This essay wants to show the different meanings of the concept of utility in the philosophy of Spinoza. On the one hand it shows itself as a tendency of human nature to search at all costs everything that would prolong the lives of individuals. On the other hand it is displayed as that which provides the largest number of prejudices to an individual: this avid pursuit leads to the field of the most delirious imagination. This is where the transfiguration of the highest right to everything and the two subjects that embody it - individuals and political society - become important. Spinoza intends to resolve the paradox between the maximization of individual power and the maximization of the conflict(,) proposing a new subject of highest right, the multitude.

Keywords: utility, law, fear, hope, desire.

\section{REFERÊNCIAS BIBLIOGRÁFICAS:}

1. Bartuschat, Wolfgang - Spinozas Theorie des Menschen, Hamburgo: Felix Meiner, 1992

2. Bennett, Jonathan -"Spinoza and teleology: a reply to Curley" in Spinoza, Issues and directions, the proceedings of the Chicago Spinoza Conference, Leiden: E. J. Brill, 1990.

3. Canetti, Elias, Masse und Macht, Hamburg: Fischer Taschenbuch Verlag, 1983.

4. Cristofolini, Paolo, Spinoza edonista, Edizioni Ets, Pisa, 2002.

5. Curley, Edwin -"On teleology" in Spinoza, Issues and directions, the proceedings of the Chicago Spinoza Conference, Leiden: E. J. Brill, 1990.

6. Elster, Jon, Tuercas y tornillos, Barcelona: ed. Gedisa, 1996.

7. Kant - La crítica del juicio, Madrid: Espasa-Calpe 1977.

8. Levinas - Difficile Liberté, Paris: Éditions Albin Michel, 1976.

9 . - De otro modo que ser, o más allá de la esencia, Salamanca: Ediciones sígueme, 1987. 
10. Macherey, Pierre, Introduction á l'Éthique de Spinoza, PUF, Paris, 1998

11. Matheron, Alexander, Individu et Comuunnautte. Paris: Les editions de Minuit, 1969. 12 - « Le problème de l'évolution de Spinoza du Traite Théologiquepolitique au Traité Politique », en Spinoza, Issues and directions, E. J. Brill, Leiden, 1990

13. Negri, Antonio, Spinoza subversif, Éditions Kimé, Paris, 1994.

14. Schewe, Martin, Rationalität contra Finalität, Spinozas Antropomorphismuskritik als Element seiner Methodenlehre, Peter Lang Verlag, Frankfurt, 1987

15. Spinoza - Etica Ed. Trotta, versión de Atilano Domínguez, Madrid, 2000.

16. Tratado Teológico-Político, Alianza Editorial, versión de Atilano Domínguez, Madrid, 1986.

17 Tratado Político, Alianza Editorial, versión de Atilano Domínguez, Madrid, 1986.

\section{NOTAS:}

1. Para una exposición detallada de la relación finalismo-antropocentrismo, consúltese a Wolfgang Bartuschat 17, p. 29-36. De acuerdo a Bartuschat, la Ética tiene una perspectiva "fisiocéntrica" (p. 35) que desplaza la imagen del hombre fuera del centro del universo. De ahí la exigencia de desplazarse del orden de las cosas al orden de las causas. Cf. también Schewe 14. La naturaleza del pensamiento antropomórfico genera un tipo de predicados (y dicotomías) que se caracterizan por orientar la acción práctica y por ser demasiado abiertos y generales. También sirven para construir prejuicios generados a partir de los universalia (p. 20). Para este punto, también es importante seguir la discusión entre Edwin Curley y Jonathan Bennett (Curley 5 y Bennett 2). La tesis de Curley es que Spinoza distingue entre teleología cósmica y teleología humana. La primera es rechazada y la segunda es explicada como una tendencia propia de la inclinación de las ficciones derivadas de la búsqueda de utilidad.

2. No es Heráclito el autor de la frase. Se trata de Spinoza 15, E. Primera Parte, Apéndice, p. 69.

3. Un ladrón me fuerza a prometerle que le daré mis bienes cuando él quiera...O supongamos que yo he prometido sin fraude a alguien que no tomaría comida ni alimento alguno durante veinte días, y que no puedo guardarla sin gravísimo daño para mí. Dado que estoy obligado, por derecho natural, a elegir de dos males el menor, tengo el máximo derecho a romper mi compromiso y a dar lo dicho por no dicho Spinoza 16, TTP, Cap. XVI, II, p. 339.
4. (Spinoza 15, E. Primera Parte, Apéndice, p. 71). "Después de que los hombres se convencieron de que todo cuanto se hace, se hace para ellos mismos, debieron considerar como lo principal en cada cosa aquello que es lo más útil para ellos y estimar como más excelentes aquellas cosas por las que mejor son afectados. Y así debieron formar estas nociones para explicar la naturaleza de las cosas, a saber, bueno, malo, orden, confusión, caliente, frío, hermosura y fealdad; y como se consideran libres, surgieron estas nociones, a saber, alabanza, vituperio, pecado y mérito. Pero éstas las explicaré más abajo...". Utilitas es, a un tiempo, impulso y, al principio, un velo cognitivo que nos impide ver más allá de las impresiones de nuestra propia constitución afectiva. En esa especie de infancia intelectual que se describe en el Apéndice de la primera parte de la Ética, lo que conviene a nuestra naturaleza no es, por tanto, una fuente de conocimiento sino una fuente de perseverancia.

5. Cf. Matheron 11, p. 249. Quizá como nadie, Alexander Matheron ha insistido en esta doble visión que tiene la antropología spinoziana. Por un lado admite que la sociedad política nace de intereses y no de pactos racionales. Por otro lado, sostiene que el principio de utilidad se llega a transmutar en la filosofía de Spinoza, en un impulso intelectualizado.

6. En el contexto de la exégesis de las obras de Spinoza causa cierto temor el término "eficiencia" y su vínculo con el concepto "razón instrumental". Pero la noción de potencia de actuar sería abstracta sin esa determinación que le dan el temor y la esperanza: estas afecciones tienen una función claramente instrumental. La especificidad de ese pulso de los resultados de la acción y la recurrencia al modelo iusnaturalista tienen todavía eco el esta tesis de Jon Elster. La raíz spinozista de la tesis de Elster consiste en que también explica la matriz de la acción en los deseos y en que, en todo momento, los resultados de ésta son permanentemente evaluados: "La elección racional es instrumental: está guiada por el resultado de la acción. Las acciones son evaluadas y elegidas no por sí mismas sino como un medio medios más o menos eficiente para otro fin". Elster 6, p. 31.

7. Cf. Macherey 10, p. 258-59. En una interpretación sugerente del Apéndice de la primera parte de la Ética, Macherey sostiene que esta tendencia abusiva que contamina a todos nuestros juicios de valor acaba por imponerse: nos importa más las cosas tal y como nos afectan, no tal y como son en sí. "Queda por comprender por qué el prejuicio finalista ocupa tal lugar en el espíritu de la gente, que acaba por relacionar todas las ideas que se hacen de las cosas. En efecto, a partir de las ocasiones particulares que lo han engendrado, se convierte en el factor de un proceso de contaminación por 
el cual se comunica progresivamente a todas las figuras usuales del pensamiento, que ha inclinado en su sentido. Así son puestas en lugar las estructuras mentales que revelan las diversas formas de evaluación que, incluso sin reflexionar, aplicamos a la realidad relacionándola a nuestra propia medida y procediendo a la identificación abusiva de lo que las cosas son para nosotros...todos nuestros juicios de valor se operan así en perspectiva, relativamente a lo que nosotros estimamos que constituye nuestro interés: eso es lo que consideramos de entrada en las cosas, aquello que son susceptibles de aportarnos o lo que pueden eventualmente generarnos, y no tal y como son en sí mismas".

8. Para que algo sea útil debe ser conmensurable, de tal manera que el primer instrumento de las decisiones sobre los bienes y los males sea una forma de tasar sus efectos positivos y negativos: "Es una ley universal de la naturaleza humana que nadie desprecia algo que considera bueno, sin no es por la esperanza de un bien mayor o por el miedo de un mal mayor...Es decir, que cada uno elegirá, de dos bienes, el que le parece mayor y, de dos males, el que le parece menor. Digo expresamente aquello que le parece mayor o menor al que elige, no que las cosas sean necesariamente tal como él las juzga. Esta ley está, además, tan firmemente grabada en la naturaleza humana, que hay que situarla entre las verdades eternas" (Spinoza 16, TTP, Cap. XVI, II, p. 338).

9. (Spinoza 15, E, Parte 1 Def. 1 y 2). Para que una cosa sea concebida como finita se necesita comparar con otra de su misma naturaleza y, en función de esta pertenencia, sostiene que un cuerpo sólo es comparable con otro cuerpo y una idea con otra idea. "Mayor" y "menor" no existen, por tanto, en el infinito.

10. ¿A qué cuestiones responde la obra política de Spinoza, particularmente su Tratado Político? A la emergencia del Estado absolutista, que se ha apropiado de la visión contractualista de la política y del individualismo competitivo. (Cf. Negri 10). El filósofo italiano encuentra razones para sostener que, con el triunfo del modelo teórico del derecho natural, se introduce también un individualismo adecuado a las nuevas exigencias de producción. Spinoza presenta así, a los ojos de Negri, una resistencia frente al absolutismo político y el absolutismo del mercado (p. 35). Aunque Negri enfatiza la crítica a la visión trascendental en el anticontractualismo de Spinoza, un filósofo de la inmanencia no puede sino partir de la experiencia y de la naturaleza humana. De ahí que el individualismo de Spinoza no sea una defensa teórica del egoísmo posesivo sino del individualismo libertario.

11. Cristofolini 4: Quizá insistiendo más en el carácter político del temor, y en una lectura en la que está espléndidamente presente la huella de Maquiavelo, Paolo
Cristofolini sostiene que en esta afección se encuentra "el mecanismo psicológico desde el cual se esbozan las instituciones civiles" (4, p. 10). Se entiende que la esperanza no sea enfatizada aquí. En otra parte de ese libro argumenta las razones del maquiavelismo de Spinoza: "un pueblo sin temor al soberano tiende fácilmente a comportamientos feroces" (4, p. 31).

12. Es lo que Spinoza denomina pudor y consternatio.

13. ¿Habría en Spinoza una crítica la esperanza religiosa? Toda la crítica a la superstición religiosa supone un desmontaje de la esperanza de la salvación personal. Se trata de la idea según la cual Dios está constituido por una voluntad indiferente (Spinoza 15, E. Primera Parte, p. 33, Esc.). Si Dios no es un juez moral, no hay salvación posible. Sin embargo, esta crítica está remitida a la duda frente a los resultados dudosos de una acción

14. La salvación (común) es una tarea de la ciudad, no de la religión. (Spinoza 16, TTP, Cap XX, IV). El patriotismo como salvación se entiende que es la práctica de la justicia y la caridad.

15. Spinoza 15, Eth. Pars Tertia, p. XIX: metus, securitas, desperatio, gaudium, conscientia morsus. La esperanza se relaciona con la incertidumbre de la eficiencia, no con la incertidumbre de las ideas.

16. El Esse est interesse, se forma como una relación inmanente del individuo con el mundo del entorno. Vivir es estar entre entes y esa es una inevitable condición de la finitud. Los "egoísmos alérgicos", dice el antagonista, se fundan en la inmanencia. Aunque Emmanuel Lévinas sostenga que el racionalismo no es un enemigo de la fe judía, la figura de Spinoza se situaría en las antípodas del pensamiento del filósofo lituano. De ahí que la disputa contra Spinoza esté centrada por Levinas, filósofo de la alteridad, en la tesis del conatus essendi y, por supuesto, en la interpretación bíblica. Cf. Los textos sobre Spinoza en Levinas 8, p. 152-169 y Levinas 9, p. 46 y 47. ¿Spinoza es el Galileo del pueblo judío? Tal parece que la demanda de levantar su excomunión, por parte de Ben Gourion, así lo confirma. Sin embargo, la rehabilitación de Spinoza, en la filosofía de Lévinas, pasa por la reivindicación misma del mundo occidental que, según el filósofo lituano, es la libertad de espíritu.

17. "Los hombres pueden procurarse mucho más fácilmente las cosas que necesitan y que sólo uniendo sus fuerzas pueden evitar los peligros que por todas partes les acechan" (Spinoza 15, E. , Cuarta Parte, pr. 35, Esc., p. 206).

18. Alexandre Matheron (12, p.263) enfatiza justamente la ausencia de una acción concertada y racional en la explicación spinoziana de la ciudad. 
19. La proposición 37 de la cuarta parte de la Ética desarrolla lo que promete el Apéndice de la primera parte y que se despliegan en sus Tratado teológico político y el Tratado político. La conexión entre el tema de la tendencia a la utilidad y los tópicos expuestos por esta proposición -la virtud como máxima forma de utilidad, el deseo de vivir bajo la guía de la razón y la definición de lo justo y lo injusto en la sociedad política- son a concebidos con una continuidad temática: "En el Apéndice de la primera parte, prometí explicar qué es la alabanza y el vituperio, el mérito y el pecado, lo justo y lo injusto...pero antes hay que decir algo acerca del estado natural y civil del hombre" (subrayado nuestro).

20. Canetti 3: Es obvio que en Spinoza no aparece la categoría "masa". Sin embargo, podemos decir que la clasificación que hace Canetti es conceptualmente adecuada a lo que Spinoza llamaría "estado natural": una masa que está dominada por sus pasiones, todavía no entra en "posesión de su potencia de actuar", es decir, todavía no deviene multitud. Crecimiento, igualdad, densidad y dirección (p. 26), sostiene Canetti, son los atributos de estos individuos que todavía no tienen soberanía y que, más bien, tienen el temor de "la mano transmutada en garra" ( $p$ 9).

21. El criterio de utilidad, dado que no puede haber una definición absoluta de ésta, no puede dársele un carácter objetivo ni uno meramente subjetivo. Spinoza propone justamente la idea de noción común no sólo como una mera categoría de la teoría del conocimiento (Spinoza 15, E. Segunda Parte, pr. 39, Cor., p. 106): “el alma es tanto más apta para percibir adecuadamente más cosas, cuantas más cosas tiene el cuerpo humano comunes con otros cuerpos". La noción común, desde el punto de vista de la valoración, no los define sino como un encuentro y composición entre ambas entidades: el sujeto deseante y lo deseado.

22. En efecto, Kant sostiene que una ética sostenida en inclinaciones es "casi instintiva" $y$, desde esa perspectiva, no hay manera de justificar a los deberes. Toda forma de acción práctica, en Kant, está arraigada en un orden nouménico desde el cual la razón se propone fines morales y, desde el cual, asimismo, se propone su realización. El deseo, o, como dice Kant, el tiempo de la "impaciente espera" tiene, con su objeto, una relación causal y, al mismo tiempo, se despliega en el vacío: "esa ilusión de los anhelos vacíos, es, pues, tan sólo la consecuencia de una bienhechora organización de nuestra naturaleza". (Kant 7, p. 77). La filosofía trascendental hace del deseo una representación, mientras que una perspectiva inmanentista hace del deseo un impulso. De ahí que se entienda que en Kant el deseo entrañe la capacidad de entrar en contradicción consigo mismo, mientras que en Spinoza, el deseo sería la fuente más primaria de entrar en concordancia con uno mismo, una manifestación del sui juris. "La salvación de la trascendencia" sería, para Kant, la condición misma del surgimiento de la cultura; para Levinas, la trascendencia permite acceder al orden de la paz mesiánica, porque está a salvo de la inmanencia del interesse. 